\title{
Heat transfer mode shift to adiabatic thermalization in near-critical carbon dioxide under terrestrial conditions
}

Anatoly Parahovnik ( $\nabla$ tolik@Knights.ucf.edu )

University of Central Florida https://orcid.org/0000-0001-9829-4227

Yoav Peles

University of Central Florida

\section{Article}

Keywords: adiabatic thermalization, piston effect, acoustic waves, heat transfer

Posted Date: February 15th, 2021

DOl: https://doi.org/10.21203/rs.3.rs-199789/v1

License: (c) (1) This work is licensed under a Creative Commons Attribution 4.0 International License.

Read Full License 


\title{
Heat transfer mode shift to adiabatic thermalization in near- critical carbon dioxide under terrestrial conditions
}

\author{
Anatoly Parahovnik ${ }^{\mathrm{a}, \mathrm{b}}$ and Yoav Peles ${ }^{\mathrm{a}, \mathrm{c}}$, \\ a 4000 Central Florida Blvd, Orlando, FL 32816 \\ b tolik@ Knights.ucf.edu \\ c yoav.peles@ucf.edu
}

Mechanical and aerospace engineering, University of central Florida, USA

\begin{abstract}
Heat transfer via acoustic waves is referred to as adiabatic thermalization or the piston effect. Until now, adiabatic thermalization was believed to be a secondary effect that mostly occurs under microgravity conditions and is readily overpowered by mixing due to gravitational forces. However, this work revealed that in microsystems, adiabatic thermalization is a dominant heat transfer mechanism. A substantial shift in thermalization modes from vaporization to acoustic waves was observed through critical opalescence temperature measurements of carbon dioxide $\left(\mathrm{CO}_{2}\right)$. The contribution of the piston's effect increased from $4.3 \%$ to $77.6 \%$ when the reduced pressure increased from 0.86 to 0.99 . The findings are used to explain the observed heat transfer enhancement that occurred concurrently with the reduction in the void fraction. Revealing the nature of the piston effect to enhance heat transfer will advance copious technological fields like space exploration, fusion reactors, data centers, electronic devices, and sensing technology.
\end{abstract}

\section{Introduction}

Heat transfer, also known as thermalization process, is a fundamental and ubiquities phenomenon that is vital to humans, and managing it is a critical part of most modern technologies. Better and more advanced heat transfer methods are critical for human-friendly environment in outer space ${ }^{1}$, development of fusion reactors that will provide clean energy to humans ${ }^{2}$, and the design of faster computers and larger 
datacenters $^{3}$. In addition to the previously known thermalization modes of radiation, diffusion, and convection, a fourth mode, known as adiabatic thermalization or the piston effect, was discovered in the $1970 \mathrm{~s}^{4}$. Under this mode, heat is dissipated through acoustic waves and is most notable near the critical conditions of fluids, where the thermophysical properties of the fluids change significantly with temperature $^{5-7}$. The effect was first observed and has been mostly researched under microgravity conditions as part of international space programs, and it was believed that adiabatic thermalization had little to no effect on heat transfer under terrestrial conditions ${ }^{8,9}$. A theoretical analysis ${ }^{10-13}$ suggested that the van der Waals equation of state captures the phenomenon with exponential functions accounting for the thermophysical properties. Additionally, the piston effect along the pseudocritical line in quiescent fluids was studied under terrestrial conditions and it was concluded that its contribution to the overall heat transfer process was insignificant ${ }^{10-12,14,15}$. This effect was also reported at slightly subcritical conditions in microgravity, where a transition from a first-order phase change process (discontinuity in the primary thermodynamic properties, e.g., density) to a second-order process (discontinuity in the derivatives of thermodynamic properties, e.g., specific heat) was observed ${ }^{16}$. Garabos et al. ${ }^{17,18}$ studied boiling of nearcritical fluids in microgravity and suggested that the effect leads to the presence of nonequilibrium liquid and gas phases and that the liquid-vapor interface becomes unstable as the critical point is approached. Until now, experiments were conducted with near-critical, stagnant fluids using experimental rigs with a characteristic length scale of cubic centimeters. Under these conditions the piston effect is most likely negligible in 1-g. However, the current study demonstrates for the first time that the piston effect can also be significant in terrestrial conditions. This was done through flow boiling experiments at the micro scale near the critical conditions of carbon dioxide $\left(\mathrm{CO}_{2}\right)$. The transition to a dominant adiabatic thermalization mode as the flow gradually approaches the critical condition of $\mathrm{CO}_{2}$ was visualized, measured, and analyzed. It was found that the ratio of thermal energy transfer via the piston effect to that via evaporation increased from 0.05 to 5.5 when the reduced pressures increased from 0.86 to 0.99 . 
The reported study uses a noninvasive, optical measurement that leverages critical opalescence to measure a fluid's bulk temperature. This in turn, was used to quantify the piston effect and to explain the associated heat transfer enhancement. The phenomenon observed is pertinent to other fluids in similar reduced conditions due to the universality principle of critical fluid ${ }^{19}$. The acoustic nature of the piston effect results in a rapid thermalization mode that transfers heat order-of-magnitude faster than the typical diffusive thermalization process. This in turn can be used for rapid cooling when heat loads shift rapidly.

A transition from a dominant vaporization mode to an adiabatic thermalization mode was observed through

measurement of the bulk temperature with critical opalescence, a universal phenomenon of fluids approaching the critical point. The underlining nature of this shift was revealed through a theoretical modeling and analysis. It was shown that as the reduced pressure increased from 0.86 to 0.99 , heat transfer due to adiabatic thermalization increases from $4.3 \%$ to $77.6 \%$ of the total heat transfer, respectively. Once the dominance of the piston effect is fully recognized, its potential to enhance heat transfer will be further explored and new research areas will be established to enable a wide range of new cooling approaches.

\section{Results}

Visual images, local surface temperature, and pressure of flow boiling of $\mathrm{CO}_{2}$ at reduced pressures $\left(P_{r}\right)$ between 0.86 and 0.99 were studied. The mass flux $(G)$, the heat flux $\left(q^{\prime \prime}\right)$, and the returned light intensity ratio $\left(I_{T_{0}} / I_{T}\right)$ are provided for each case in Table 1.

\section{Flow boiling patterns}

Two distinct boiling patterns were observed, depending on the reduced pressure of the fluid. For reduced pressures below 0.95 , a pattern of nuclei bubbles with diameters ranging from $2 \mu \mathrm{m}$ to $5 \mu \mathrm{m}$ formed on the heated surface. The bubbles propagated downstream and expanded up to a diameter of $\sim 50 \mu \mathrm{m}$. The bubbles also maintained a spherical shape and formed a vapor-less region in their wake as they moved downstream with a distinct and well-defined vapor-liquid boundary, see Fig. 1a. For reduced pressures above 0.95, the nuclei sites produced bubbles smaller than $2 \mu \mathrm{m}$ that were more densely populated and moved slower 
downstream forming a dusky blanket on the heated surface that eventually grew into elongated streaks. The vapor-liquid boundary of the streaks was blur, and no discontinuity in the dusky blanket or presence of vapor-less area upstream were observed, see Fig. 1b. The blurring process of the vapor-liquid boundary layer and the deviation from spherical shape was consistent with observations from microgravity experiments and is related to a shift in the dominant thermalization mode ${ }^{17}$. Supplementary Fig. 1 presents the remaining flow pattern that were observed.
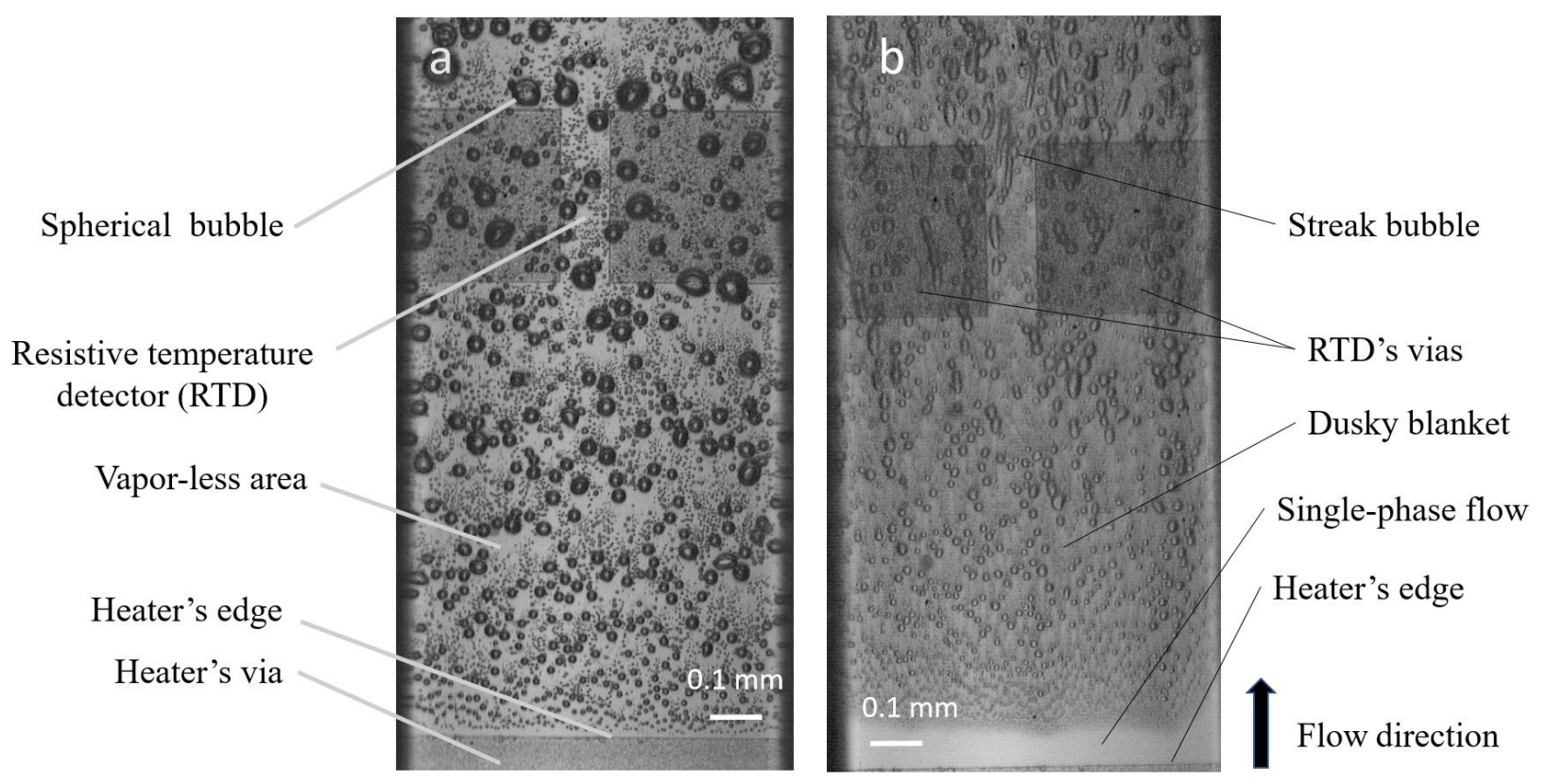

Figure. 1. Shift in flow pattern as the reduced pressure approaches unity: a) At reduced pressures below 0.95 , nuclei bubbles with an initial diameter of $2 \mu \mathrm{m}$ to $5 \mu \mathrm{m}$ formed and gradually grew to diameter of $\sim 50 \mu \mathrm{m}$ (shown: $P_{r}=0.86, G=523 \mathrm{~kg} / \mathrm{m}^{2} \mathrm{~s}$, and $q^{\prime \prime}=7.14 \mathrm{~W} / \mathrm{cm}^{2}$ ) as they propagated downstream. As the bubble grew, they formed vapor-less regions in their wake. b) At reduced pressures above 0.95, a bi-pattern composed of vapor streaks above the heater and small $\sim 2 \mu \mathrm{m}$ nuclei bubbles, which formed inside a distinct dusky layer below the heater was observed (shown: $P_{r}=0.98, G=474 \mathrm{~kg} / \mathrm{m}^{2} \mathrm{~s}$, and $q^{\prime \prime}=9.2 \mathrm{~W} / \mathrm{cm}^{2}$ ). Vapor downstream propagation was considerably slower compared to lower pressures. The change in bubble shape and pattern was consistent with experimental studies performed in a microgravity environment ${ }^{17}$. 
Liquid $\mathrm{CO}_{2}$ reached the heater with subcooled temperatures ranging from $7.61 \mathrm{~K}$ to $1.37 \mathrm{~K}$, depending on the operational pressure. As the pressure approached the critical condition, the void fraction, i.e., the fraction of the channel cross-sectional area occupied by the gas phase, decreased, as shown in Fig. 2a. Since the bubble ebullition process is associated with vaporization and flow mixing — processes that enhance heat transfer - a reduced void fraction can be associated with a lower heat transfer coefficient ${ }^{20}$. Furthermore, the latent heat of vaporization, $h_{f g}$, diminishes with increasing pressure ${ }^{21}$, and thus, the potential to enhance heat transfer due to the liquid-to-vapor phase change is expected to deteriorate with pressure. However, as shown in Fig. 2b, the heat transfer coefficient (HTC), experimentally obtained by Parahovnik et al. ${ }^{22}$ and by the correlation of Cheng et al. ${ }^{23}$, suggest otherwise. Below we show that this increase is directly related to the piston effect, previously believed to be dominant only under microgravity conditions at reduced pressures near unity.
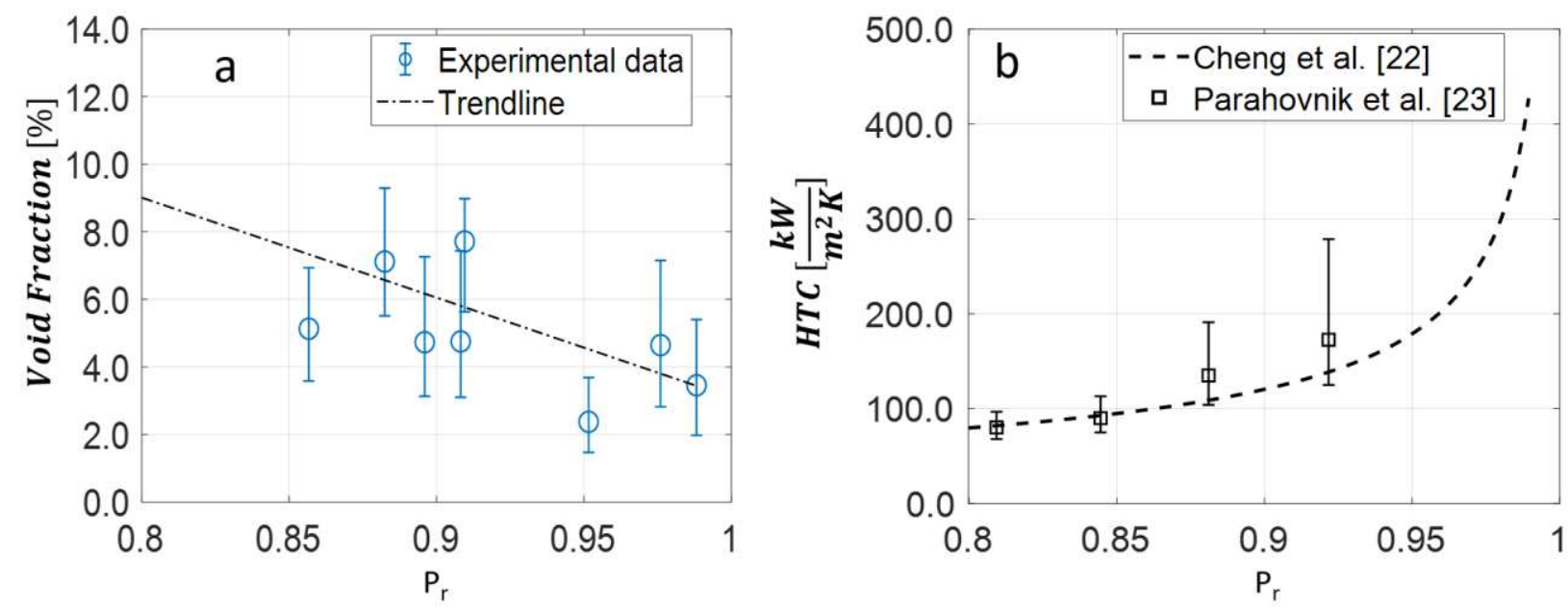

Figure. 2. Vapor fraction and heat transfer coefficient trends as the reduced pressure approached unity. a) The void fraction decreased with reduced pressure, while b) the heat transfer coefficient increased. 


\section{Opalescence measurements of the fluid.}

The piston effect was quantified through critical opalescence measurements of the bulk liquid temperature ${ }^{24-29}$. When the fluid's temperature approaches the critical condition, intermolecular fluctuations lead to higher light scattering, which promotes fluid's opaqueness ${ }^{27}$. During experiment, the microchannel was illuminated and the reflected light was captured and quantified by the camera. The ratio between the scattered to the induced light and its relation to fluid's state is quantified by Eq. $1^{29,30}$.

$$
\begin{gathered}
R=\frac{I_{i}-I}{I_{i}} \\
R=\frac{k_{B} \cdot \pi^{2}}{2 \cdot \lambda_{o}^{4}} \cdot T \cdot \beta \cdot\left(\rho \cdot \frac{\partial \varepsilon}{\partial \rho}\right)_{T}^{2}
\end{gathered}
$$

Where $R$ is the ratio of the scattered to the induced light, $I_{i}$ is the induced light intensity, $I$ is the returned light intensity, $\kappa_{B}$ is the Boltzmann constant, $T$ is the fluid's temperature, $\lambda_{o}$ is the primary incident light wavelength, $\beta$ is the isothermal compressibility, $\varepsilon$ is the dielectric constant, $\rho$ is the density, and the term $(\rho \cdot \partial \varepsilon / \partial \rho)^{2} T$ is given by Einstein $^{31}$.

The scattering ratios due to critical opalescence are considerably lower than unity ${ }^{32}$, and the expected temperature differences were low due to boiling inception. A relation between the fluid's temperature and the returned light intensity ratio was formulated according to Eq. 2. (For additional details see 'Derivation of the returned light intensity ratios and fluid temperature relation' in the supplementary material.)

$$
\frac{I_{T_{0}}}{I_{T}}=\frac{R_{T}}{R_{T_{0}}}=\frac{\frac{k_{B} \cdot \pi^{2}}{2 \cdot \lambda_{0}^{4}} \cdot T \cdot \beta_{T} \cdot\left(\rho \cdot \frac{\partial \varepsilon}{\partial \rho}\right)_{T}^{2}}{\frac{k_{B} \cdot \pi^{2}}{2 \cdot \lambda_{0}^{4}} \cdot T_{0} \cdot \beta_{T_{0}} \cdot\left(\rho \cdot \frac{\partial \varepsilon}{\partial \rho}\right)_{T_{0}}^{2}}=\frac{T \cdot \beta_{T} \cdot\left(\rho \cdot \frac{\partial \varepsilon}{\partial \rho}\right)_{T}^{2}}{T_{0} \cdot \beta_{T_{0}} \cdot\left(\rho \cdot \frac{\partial \varepsilon}{\partial \rho}\right)_{0}^{2}}
$$

The coefficients (i.e., $k_{B}, \lambda_{o}$, and $\pi$ ) were canceled-out from the equation. The returned light intensity ratios were measured by converting the camera images to bitmap image files. (The stronger the returned light intensity is, the higher the pixel's numerical value at a specific location.) Subsequently, the returned light intensity profile was calculated by averaging its values perpendicular to the flow excluding the influence of the bubbles. The returned light intensity at the inlet temperature (i.e., $I_{T_{0}}$ where $T_{0}$ is the inlet temperature) 
of the fluid was sampled close to the heater's edge before boiling inception. The downstream returned light intensity (i.e., $I_{T}$ where the subscript $T$ stands for the hotter temperature) was tested before the resistive temperature detector's (RTD's) vias at $0.9 \mathrm{~mm}$ from the heater's edge to avoid background interference, see Fig. 3. For reduced pressures below 0.95 , the fluctuations of the returned light intensity data were considerable while for reduced pressures above 0.95 , the presence of bubble appeared to moderate the noise from the returned light signal. Intensity measurements of all the discussed cases are provided in the supplementary materials in a section titled 'Measurements of the returned light intensity ratio.'
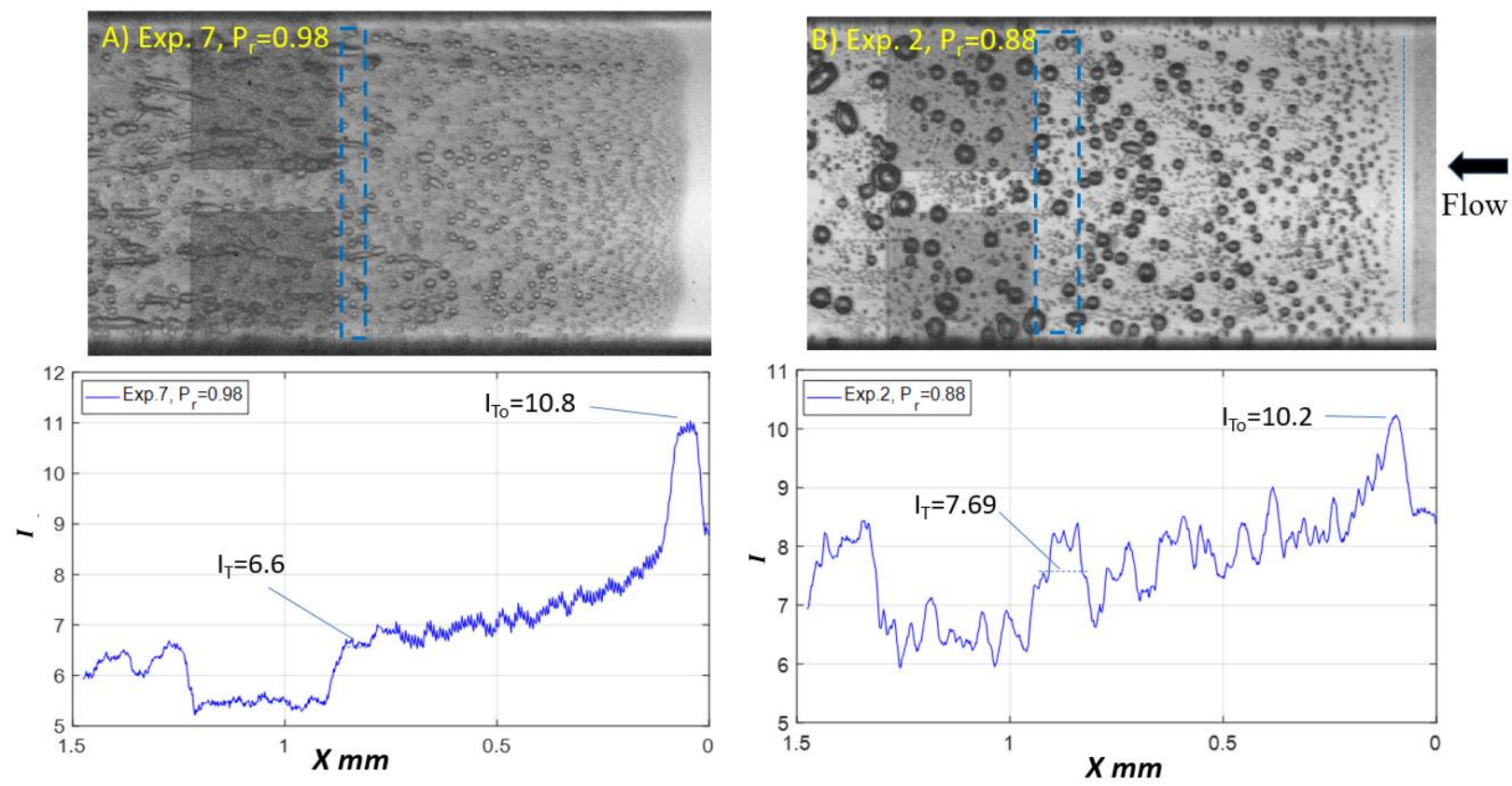

Figure. 3. Returned light intensity along the flow direction. The intensity of the returned light $(I)$ was calculated as an average of the local intensities of the cross-section. The returned light intensity at the inlet temperature $\left(I_{T o}\right)$ was sampled as close as possible to the heaters via. The returned light intensity at the downstream temperature was sampled before the RTD's vias to maintain similar background. The mean returned light intensity of the cross-section dropped as the flow was heated. The bubbles were expressed as variations from the mean returned light intensity value. As the reduced pressure approached unity, these variations were reduced to moderate signal noise. 
The fluid inlet temperature, $T_{0}$, was measured using a thermocouple that was externally integrated into the experimental setup. Since no preheating was applied, the fluid was in thermal equilibrium with the thermocouple. The Span and Wagner equation of state $^{33}$ with the aid of NIST REFPROP ${ }^{\circledR 21}$ software were used to calculate the isothermal compressibility, $\beta_{T}$ and $\beta_{T_{0}}$. The two terms, $(\rho \cdot \partial \varepsilon / \partial \rho)_{T}^{2}$ and $(\rho \cdot \partial \varepsilon / \partial \rho)_{T_{0}}^{2}$, were calculated through the equation proposed by Eykman ${ }^{34}$, which is an empirical relation that links the $(\rho \cdot \partial \varepsilon / \partial \rho)^{2}$ term to the fluid's refractive index, $n$, see Eq. 3.

$$
\left(\rho \cdot \frac{\partial \varepsilon}{\partial \rho}\right)_{T}=\frac{2 \cdot n \cdot(n+0.4) \cdot\left(n^{2}-1\right)}{n^{2}+0.8 \cdot n+1}(3)
$$

Carbon dioxide's refractive index, $n$, was measured by Moriyoshi et al. ${ }^{35}$, and it was found that it depends on both the temperature and the pressure. For the current study, the refractive index ranged from 1.17 to 1.25, which was used in Eqs. 2 and 3.

Figure 4 depicts the ratio of the light scattering ratio (i.e., $R_{T} / R_{T_{0}}$ ) as a function of temperature difference (i.e., $\Delta T_{R}=T-T_{0}$ ) from $0 \mathrm{~K}$ to $6 \mathrm{~K}$ for experiment one through eight, see Table 1. By comparing the returned light intensity ratio (i.e., $I_{T_{0}} / I_{T}$ ) with the light scattering ratio (i.e., $R_{T} / R_{T_{0}}$ ), the temperature difference was inferred. This temperature difference corresponded to the increase in the fluid temperature that was measured through the critical opalescence effect. 


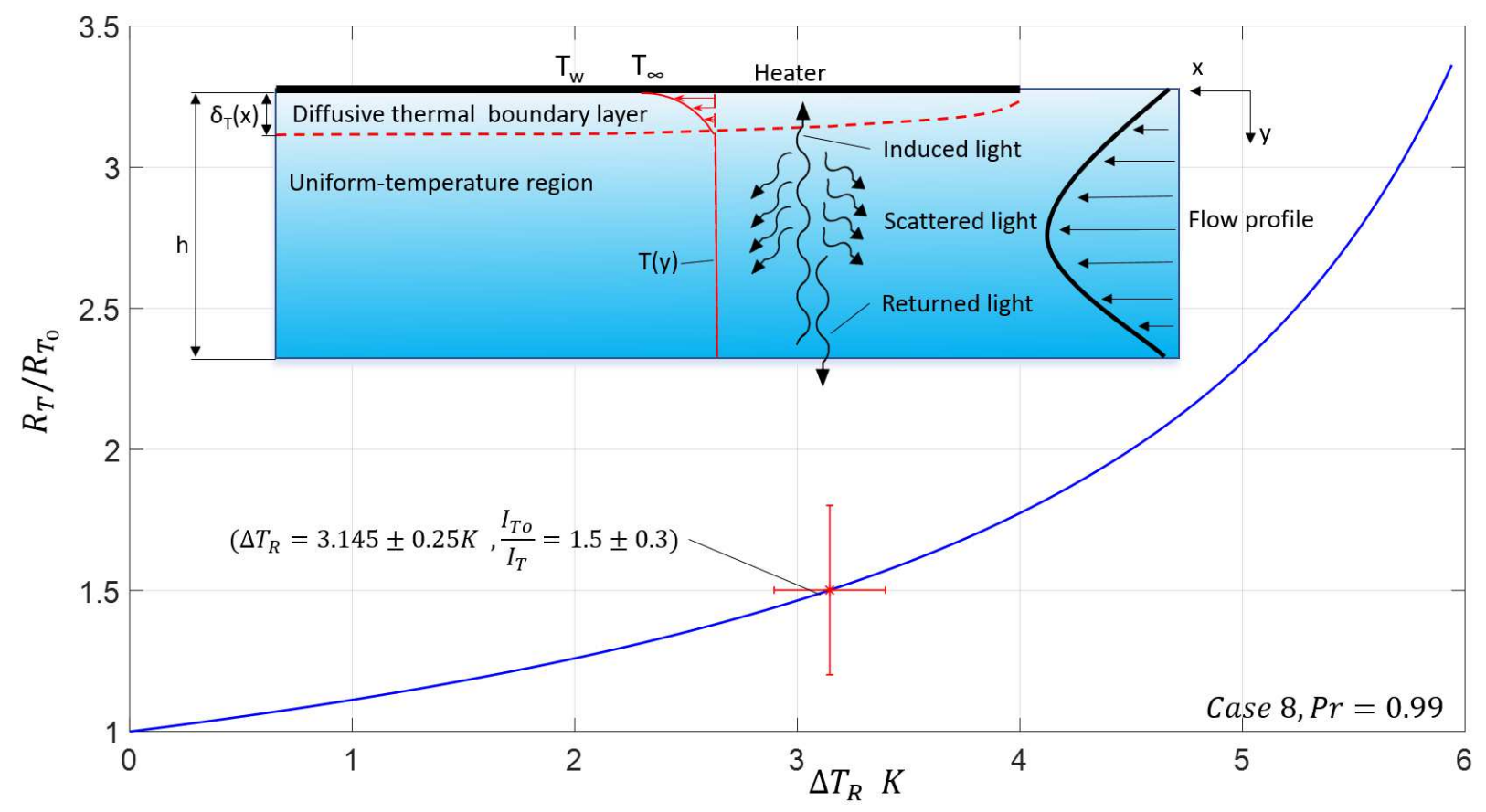

Figure. 4. Calculation of the increase in temperature according to returned light density

measurements. The scattering ratio $\left(R / R_{T o}\right)$ as a function of the bulk temperature increase $\left(\Delta T_{R}\right)$ at a reduced pressure of 0.99 . The theoretical curve obtained from Eq. 2 corresponds to a measured value of 1.5 at a temperature rise of $3.145 \mathrm{~K}$.

The diffusive boundary layer theory ${ }^{36}$ was used to predict the fluid temperature distribution. The thermal boundary layer height was calculated using Eq. 6 and was predicted to range from $8.8 \mu \mathrm{m}$ to $13.2 \mu \mathrm{m}$, see insert in Fig. 4. (See additional samples in supplementary material 'Inferring the bulk fluid temperature.') Therefore, the region with uniform temperature (i.e., outside the thermal boundary layer) corresponded to $86.8 \%-91.2 \%$ of the channel's volume. Thus, about $~ 90 \%$ of the light scattering took place in a region of uniform temperature, suggesting that the optical signature that reached the camera mostly reflected the changes in the fluid's bulk temperature. Hence, the fluid's bulk temperature, rather than the diffusive boundary layer temperature, was sampled. 


\section{Calculation of the downstream bulk temperature with the piston effect}

The piston effect is a thermalization mode that transfers heat outside the diffusive boundary layer. The temperature increase $\left(\Delta T_{p}\right)$ outside the diffusive boundary layer due to the piston effect was formulated by Onuki et al. ${ }^{30}$ :

$$
\Delta T_{p}=(\gamma-1) \cdot \frac{V_{1}}{V_{1}+V_{2}} \cdot \Delta T_{d i f f}
$$

Where $\Delta T_{\text {diff }}$ is the temperature difference between the diffusive thermal boundary layer temperature and the inlet temperature, $\gamma$ is the ratio of the specific heat at constant pressure to specific heat at constant volume, $V_{l}$ is the volume of the diffusive boundary layer (i.e., a volume with a depth of $\delta_{T}(x)$ ), and $V_{2}$ is the remaining fluid volume (i.e., a volume with a depth of $h-\delta_{T}(x)$, where $h$ is the channel height), see Fig. 4. Since the width and length of $V_{1}$ and $V_{2}$ were the same, they were canceled out, making the volume ratio equal to $\delta_{T}(x) / h$. For subcooled boiling, it is reasonable to assume that the temperature within the boundary layer corresponded to the fluid's saturation temperature $\left(T_{\text {sat }}\right)^{20}$, while the fluid temperature outside the boundary layer corresponds to the inlet temperature $\left(T_{0}\right)$. Therefore, $\Delta T_{\text {diff }}$ in Eq. 5 was reformulated as the difference between the saturation temperature and the inlet temperature (i.e., $\Delta T_{\text {diff }}=\Delta T_{\text {sub }}=T_{\text {sat }}-T_{0}$ ). Consequently, the temperature increase due to the piston effect was determined by the following equation:

$$
\Delta T_{p}=(\gamma-1) \cdot \frac{\delta_{T}(x)}{h} \cdot \Delta T_{s u b}
$$

The thermal boundary layer thickness, $\delta_{T}(x)$, was determined according to ${ }^{36}$ :

$$
\delta_{T}(x)=x / \sqrt{ }\left(C p_{l} \cdot D_{h} \cdot G / \kappa\right)(6),
$$


where $x$ is the distance from the leading edge of the heater (i.e., $x=0.9 \mathrm{~mm}$ ), $C p_{l}$ is the specific heat at constant pressure, $D_{h}$ is the hydraulic diameter of the channel (i.e., $D_{h}=0.31 \mathrm{~mm}$ ), and $k$ is the thermal conductivity of the fluid at the inlet temperature and pressure. The Span and Wagner equation of state ${ }^{33}$ with the aid of NIST REFPROP ${ }^{\circledR 21}$ software was used to calculate the specific heat and thermal conductivity.

Figure 5 depicts the experimentally measured increase in the bulk fluid temperature obtained through the returned light intensity ratio (i.e., $\Delta T_{R}$ ) and the increase in the bulk fluid temperature due to the piston effect (i.e., $\Delta T_{P}$ ). The uncertainties of $\Delta T_{P}$ originated from the pressure, mass flux, and temperature measurements described in the method section. Besides the uncertainty of $\Delta T_{R}$, the uncertainty of the returned light intensity ratio was also considered. The mean average error between $\Delta T_{R}$ and $\Delta T_{P}$ was calculated to be $35 \%$, providing sufficient confidence that the fluid's bulk temperature outside the boundary layer increased mainly due to the piston effect.

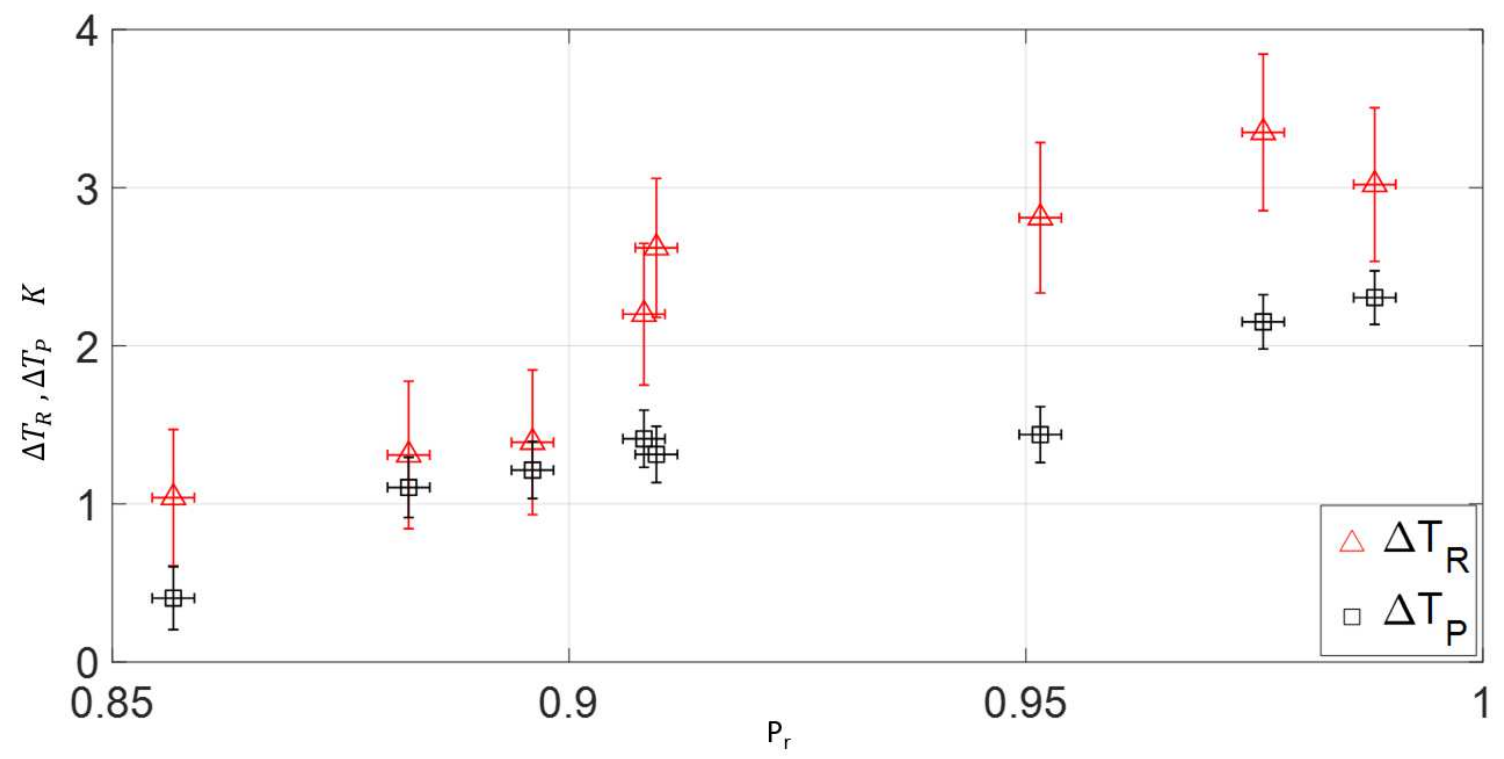

Figure. 5. Increase in bulk's fluid temperature through the piston effect analysis $\left(\Delta T_{P}\right)^{39}$ and through critical opalescence measurements $\left(\boldsymbol{\Delta} \boldsymbol{T}_{\boldsymbol{R}}\right)$. The mean average error between $\Delta T_{R}$ and $\Delta T_{P}$ was $35 \%$ provided sufficient confidence that the fluid's bulk temperature outside the boundary layer increased mainly due to the piston effect. 


\section{The relative importance of thermal transport due to the piston effect}

For a fluid near its critical condition, heat transfer is a result of three main processes consisting of convective $\left(\dot{E}_{c}\right)$, vaporization $\left(\dot{E}_{v}\right)$, and adiabatic thermalization $\left(\dot{E}_{p}\right)$ :

$$
\dot{E}_{T}=\dot{E}_{c}+\dot{E}_{v}+\dot{E}_{p}
$$

Where $\dot{E}_{T}$ is the total heat transfer rate. (Note that radiation heat transfer was neglected as the temperatures were sufficiently low.)

The piston effect is given by ${ }^{19,30,37}$ :

$$
\dot{E}_{p}=\dot{m} \cdot C p_{l} \cdot \Delta T_{p}
$$

where $\dot{m}$ is mass flow rate. The other modes were calculated according to:

$$
\begin{aligned}
& \dot{E}_{c}=\dot{m} \cdot C_{P_{l}} \cdot \Delta T_{s u b} \\
& \dot{E}_{v}=\dot{m}_{v} \cdot h_{f g}
\end{aligned}
$$

where $\Delta T_{s u b}$ is the temperature difference between the saturation and inlet temperatures, $h_{f g}$ is the latent heat of evaporation, and $\dot{m}_{v}$ is the vapor mass flow rate due to vaporization. While convective heat transfer and boiling heat transfer (i.e., vaporization) occur within the diffusive boundary layer adjacent to the heater, the piston effect transmits the thermal energy directly into the fluid's bulk, bypassing the diffusive boundary layer.

Figure. 6 shows the decomposition of the heat transfer components for $\mathrm{CO}_{2}$ at an inlet temperature of 296 $\mathrm{K}$ and reduced pressures ranging from 0.86 up to 0.99 . As the enthalpy of vaporization diminished as the fluid approached the critical conditions so did the contribution of vaporization to the total heat transfer. The increase in convective heat transfer with pressure was negligible relative to the change in the other heat transfer modes and occurred due to the rise of $T_{s a t}$ that in turn increased $\Delta T_{s u b}$. The heat transfer due to the piston effect increased significantly and had the strongest effect on the fluid's ability to carry heat with 
increasing pressure. The significant increase in the contribution of the piston effect was due to the discontinuity of the specific heat ratio $(\gamma)$ - a typical behavior of a second-order phase transition of fluids ${ }^{25}$. For reduced pressure of 0.86 , the heat transfer rate per unit mass flow rate due to convective, vaporization, and the piston effects were equal to $7.6 \mathrm{~kJ} / \mathrm{kg}, 123.4 \mathrm{~kJ} / \mathrm{kg}$, and $5.9 \mathrm{~kJ} / \mathrm{kg}$, corresponding to $5.6 \%, 90.1 \%$, and $4.3 \%$ of the total heat, respectively. The relative importance of these effects changed drastically at a reduced pressure of 0.99 , and were equal to $27.6 \mathrm{~kJ} / \mathrm{kg}, 46 \mathrm{~kJ} / \mathrm{kg}$, and $254.4 \mathrm{~kJ} / \mathrm{kg}$, corresponding to $8.4 \%$, $14 \%$, and $77.6 \%$ of the total heat transfer, respectively. The increased total heat transfer was consistent with enhanced heat transfer coefficient at higher pressures shown in Fig. $2 b$.

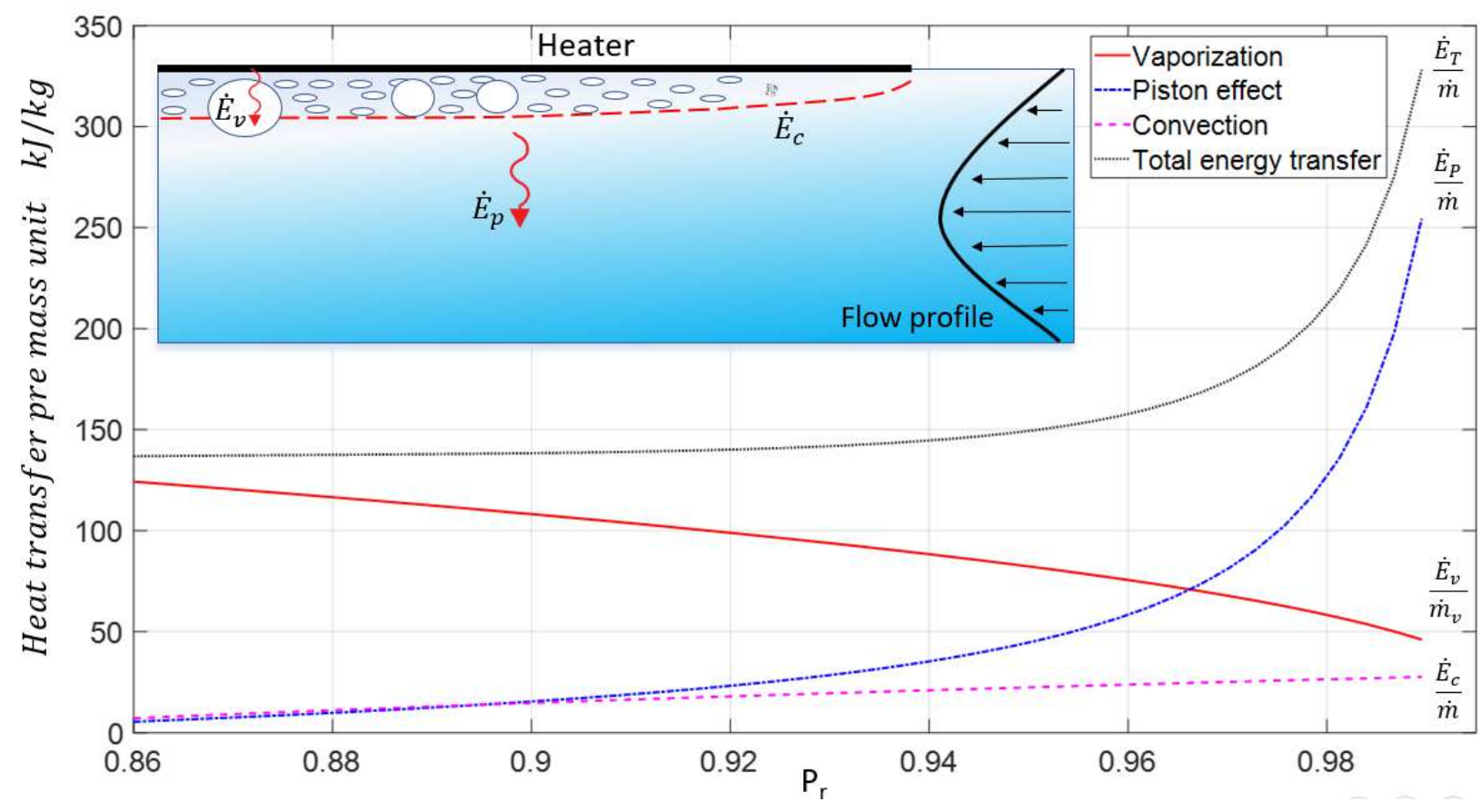

Figure. 6. Transition of heat transfer modes towards adiabatic thermalization (i.e., piston effect). The total heat transfer per mass unit ( $\frac{\dot{E}_{T}}{\dot{m}}$, dotted black curve), the vaporization heat transfer per mass unit $\left(\frac{\dot{E}_{v}}{\dot{m}_{v}}\right.$, bold red curve), the convective heat transfer per mass unit $\left(\frac{\dot{E}_{c}}{\dot{m}}\right.$, dashed blue curve), and the heat transfer due to the piston effect per mass unit $\left(\frac{\dot{E}_{P}}{\dot{m}}\right.$, pink dashed line). The heat transfer mechanism shifted from evaporation ( $90.1 \%$ to $14 \%$ for reduced pressure of 0.86 and 0.99 , respectively) to the adiabatic thermalization ( $4.3 \%$ to $77.6 \%$ for reduced pressure of 0.86 and 0.99 , respectively). While convective heat 
transfer maintained a relatively constant portion of the total heat transfer $(5.6 \%$ to $8.4 \%$ for reduced pressure of 0.86 and 0.99 , respectively). The increased total heat transfer was consistent with the enhanced heat transfer coefficient at higher pressures shown in Fig. $2 b$

\section{Discussion}

In this work, the piston effect in the vicinity of the critical condition was experimentally studied and quantified for flow boiling heat transfer under terrestrial gravity. Initially, remote local temperature measurements without flow markers were obtained employing the opalescence effect near the critical condition. Subsequently, the data was compared with theoretically calculated temperature increase of fluid's bulk due to the piston effect. The results showed that a reduction in void fraction coincided with an enhanced heat transfer coefficient.

The nature of the shift between low-pressure thermalization (i.e., boiling) associated with a first-order phase change process and the near-critical pressure thermalization processes dominated by a second-order phase change (i.e., the piston effect) was revealed. For the first time, this work demonstrated the shift from boilingdominated heat transfer to adiabatic thermalization (i.e., acoustic thermalization) for flow boiling under terrestrial gravity, which led to a significant increase in the heat transfer coefficient. The dominance of the piston effect in forced flow at the micro scale is partially attributed to the laminar regime typical of flow in microsystem in which mixing is suppressed and to the declining effect of gravity with length scale. These conditions have not yet been visualized for near-critical fluids. The adiabatic thermalization mode at the micro scale under terrestrial conditions can be used to manage high-frequency thermal loads, like radar, laser systems and a range of high-frequency applications. The nature of heat transfer pertinent to the piston effect is poorly understood, but if properly revealed, it holds great potential to revolutionize copious critical technologies that depend on effective thermal transport. 


\section{Methods}

\section{Microfluidic device and its package ${ }^{22}$}

A 100- $\mu \mathrm{m}$ high, 27-mm long and 1-mm wide optically transparent microchannel was micromachined from a 5-mm-thick fused silica substrate. The microchannel cover was fabricated using microfabrication processes from a 0.5 -mm-thick fused silica wafer and contained a heater and RTDs. The cover was sputtered with thin layers of metals ( $7 \mathrm{~nm}$ of titanium, $30 \mathrm{~nm}$ of platinum, and $1 \mu \mathrm{m}$ aluminum), which were later partially etched to form the heater and RTDs. A 1.1- $\mu \mathrm{m}$ silicon oxide layer insulated the heater and the RTDs. The outer insulation layer was polished to a surface roughness of $150 \mathrm{~nm}$. The microfluidic device was placed inside a custom-made package that guarded the device's structural integrity and enabled electrical and optical access into the microchannel. This package was made from two main stainless-steel parts and had electrical wiring to connect the device to the experimental setup (Fig. 6).

\section{Experimental rig ${ }^{22}$}

From the $\mathrm{CO}_{2}$ supply tank, the fluid was introduced into a pressurizing vessel containing a moving piston. From the backside, the piston was balanced with nitrogen, which enabled an operational pressure between 6.32 $\mathrm{MPa}$ and 7.29 $\mathrm{MPa}$, corresponding to a reduced pressure ranging from 0.86 to 0.99 , respectively. At the desired pressure, the $\mathrm{CO}_{2}$ was introduced into the package. To exclude the pressure drops along the tubing and to obtain the pressure drop in the microchannel two pressure transducers $\left(\mathrm{Omega}^{\circledR}\right)$ were placed at the inlet and outlet of the package. The $\mathrm{CO}_{2}$ flow was measured by a mass flow meter (Alicat® Model M-20SLPM-D®) and regulated using two metering values (Swagelok ${ }^{\circledR}$ S series valve). The valves were placed in serial configuration to enable double stage pressure discharge and were heated by a flexible wire heater (BriskHeat ${ }^{\circ} \mathrm{HWC} 1180$ ) to avoid solidification of the $\mathrm{CO}_{2}$ due to the depressurizing process. The experimental rig was an open fluidic system that allowed the decoupling of the pressure and mass flux to better control the operating parameters. 
The package was mounted in the optical field of a microscope (Zeiss ${ }^{\circledR}$, Observer Z.1m) with a $\times 10$ magnification lens $\left(\right.$ Zeiss $^{\circledR}$, EC-epiplan $^{\circledR}$ ), and a white light source was used to illuminate the sample. A high-speed camera (Phantom ${ }^{\circledR}$ MIRO $310 \mathrm{M}^{\circledR}$ ) was used to record the flow boiling patterns. The package was connected to a measurement and control (MC) hardware that included a DC power supply (Kysight ${ }^{\circledR}$, E3645 $\mathrm{A}^{\circledR}$ ), multimeters $\left(\right.$ Agilent $^{\circledR}, 34410 \mathrm{~A}^{\circledR}$ ), and sampling equipment (National Instruments ${ }^{\circledR}$, SCXI $1000^{\circledR}$, and DAQ $9178^{\circledR}$ ) (Fig. 7).

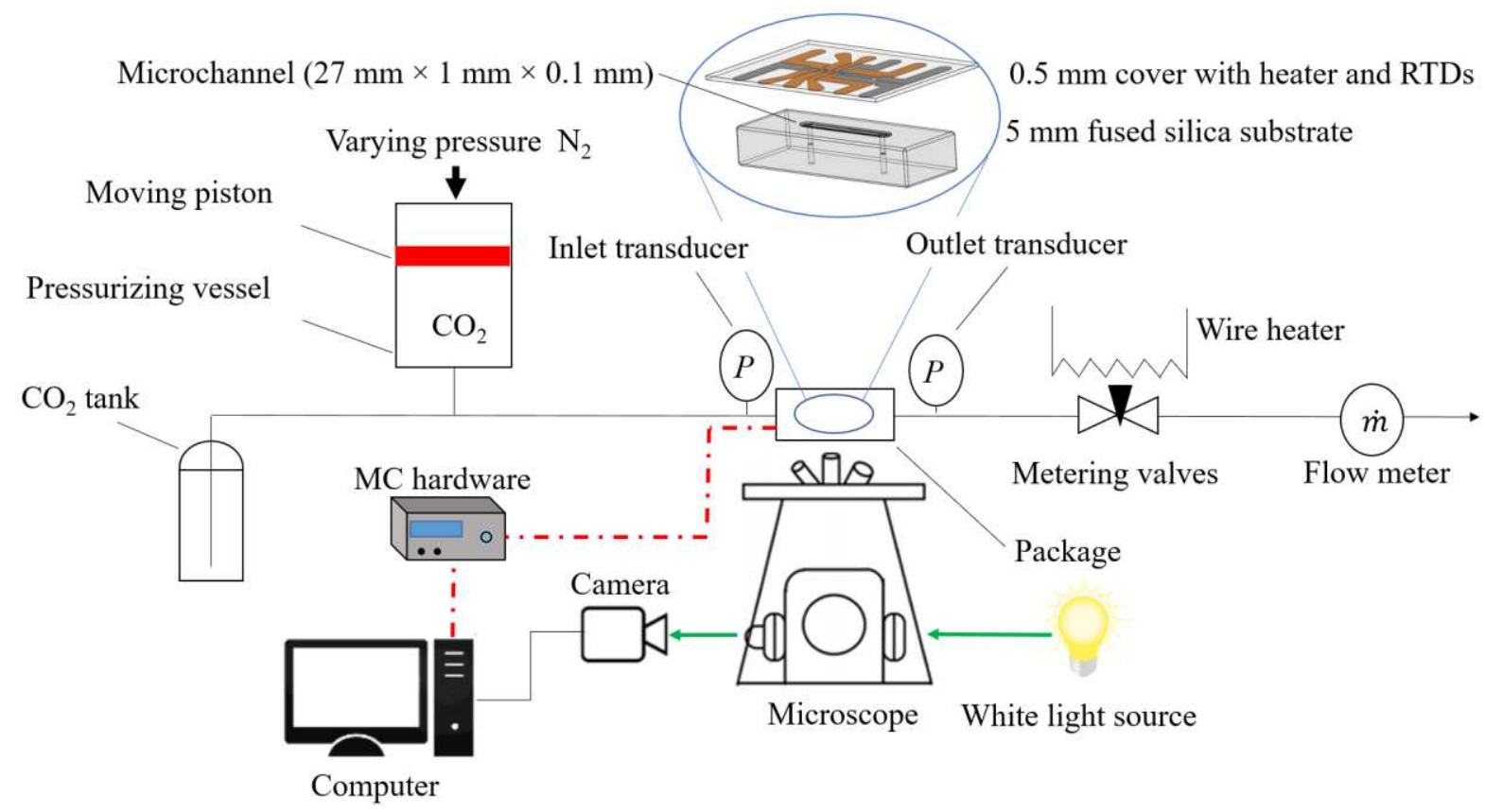

Figure. 7. Experimental setup and microfluidic device.

\section{Experimental procedure}

Once the $\mathrm{CO}_{2}$ was introduced into the microchannel, a voltage was applied to the heater inside the microchannel, an increase in the monitored temperatures was verified, and the appearance of boiling was visually validated through real-time high-speed camera recording. The camera's parameters were maintained at $7.4 \mathrm{kHz}$ with an exposure time of $9 \mu \mathrm{s}$ throughout the experiments. Ramp up times were short due to the small scale of the microfluidic device. Regardless, 20 seconds of stable readings and visual data 
were obtained before the experimental measurements were recorded. The recorded visual data contain 1,240 individual frames, each of which formed a TIFF file spanning $0.167 \mathrm{~s}$.

\section{Data reduction, uncertainty analysis}

Bubble sizes and velocities were manually measured with a virtual roller embedded in the camera's operational software (Phantom ${ }^{\circledR} \mathrm{CV}$ 3.4). Experimental uncertainties were estimated using the propagation of uncertainty analysis ${ }^{38}$ and resulted in a pressure uncertainty estimate of $\pm 0.017 \mathrm{MPa}$, a bulk temperature uncertainty estimate of $\pm 0.33 \mathrm{~K}$, and a mass flux uncertainty estimate of $\pm 10 \mathrm{~kg} / \mathrm{m}^{2} \mathrm{~s}$. The vapor fraction uncertainty was defined as an error of two pixels for each measured bubble and propagated into the total vapor volume calculation using a worst-case scenario. It resulted in variable uncertainties resulting in vapor fraction uncertainties that ranged from $16 \%$ to $57 \%$. The returned light ratio uncertainties were evaluated by identifying a possible range of the signal's mean trend. The reading propagated into the ratio calculation and produced a stable uncertainty for all cases that ranged from $2.5 \%$ to $7.4 \%$ for reduced pressures of 0.86 and 0.99 , respectively.

The returned light ratio uncertainties resulted in absolute temperature uncertainty of $\pm 0.25 \mathrm{~K}$ to $\pm 0.35 \mathrm{~K}$ for reduced pressures of 0.86 and 0.99 , respectively. Thus, both returned light intensity and bulk temperature uncertainties contributed to the total uncertainty of $\Delta T_{R}$ that ranged from $\pm 0.43 \mathrm{~K}$ to $\pm 0.5 \mathrm{~K}$ for reduced pressure of 0.86 and 0.99 , respectively. Finally, the piston effect temperature increase $\left(\Delta T_{P}\right)$ was evaluated using bulk temperature and pressure uncertainties, which resulted in $\pm 0.18 \mathrm{~K}$ and $\pm 0.14 \mathrm{~K}$ for reduced pressure of 0.86 and 0.99 , respectively.

\section{Acknowledgments}

This work was funded mainly by the Office of Naval Research (ONR) under award number N00014-18-12362 with Dr. Mark Spector as a program manager and the Israel Ministry of Defense (IMOD). The authors would like to acknowledge the Cornell NanoScale Science \& Technology Facility (CNF) for staff support, 
help, and use of facilities to fabricate the microdevices. The CNF is a member of the National Nanotechnology Coordinated Infrastructure (NNCI), which is supported by the National Science Foundation.

\section{References}

1. Ghidini, T. Materials for space exploration and settlement. Nature Materials 17, 846-850 (2018).

2. Vesely, L., Dostal, V. \& Entler, S. Study of the cooling systems with S-CO2 for the DEMO fusion power reactor. Fusion Engineering and Design 124, 244-247 (2017).

3. van Erp, R., Soleimanzadeh, R., Nela, L., Kampitsis, G. \& Matioli, E. Co-designing electronics with microfluidics for more sustainable cooling. Nature 585, 211-216 (2020).

4. Sengers, J. V. \& Moldover, M. R. Critical Phenomena Experiments in Space. ZEITSCHRIFT FUR FLUGWISSENSCHAFTEN UND WELTRAUMFORSCHUNG 2, 371-379 (1978).

5. Carlès, P. A brief review of the thermophysical properties of supercritical fluids. The Journal of Supercritical Fluids 53, 2-11 (2010).

6. Boukari, H., Shaumeyer, J. N., Briggs, M. E. \& Gammon, R. W. Critical speeding up in pure fluids. Phys. Rev. A 41, 2260-2263 (1990).

7. Zappoli, B. \& Carles, P. The thermo-acoustic nature of the critical speeding up. European journal of mechanics. B, Fluids 14, 41-65 (1995).

8. Nakano, A. \& Shiraishi, M. Visualization for heat and mass transport phenomena in supercritical artificial air. Cryogenics 45, 557-565 (2005).

9. Nakano, A. \& Shiraishi, M. Piston effect in supercritical nitrogen around the pseudo-critical line. International communications in heat and mass transfer 32, 1152-1164 (2005).

10. Miura, Y. et al. High-speed observation of the piston effect near the gas-liquid critical point. Physical Review E 74, 010101 (2006). 
11. Carles, P. \& Zappoli, B. The unexpected response of near-critical fluids to low-frequency vibrations. Physics of Fluids 7, 2905-2914 (1995).

12. Raspo, I., Meradji, S. \& Zappoli, B. Heterogeneous reaction induced by the piston effect in supercritical binary mixtures. Chemical engineering science 62, 4182-4192 (2007).

13. Zappoli, B. Influence of Convection on the Piston Effect. 13.

14. Garrabos, Y. et al. Relaxation of a supercritical fluid after a heat pulse in the absence of gravity effects: Theory and experiments. Physical Review E 57, 5665 (1998).

15. Kogan, A. B., Murphy, D. \& Meyer, H. Rayleigh-Bénard convection onset in a compressible fluid: 3 He near T C. Physical review letters 82, 4635 (1999).

16. Barmatz, M., Hahn, I., Lipa, J. A. \& Duncan, R. V. Critical phenomena in microgravity: Past, present, and future. Reviews of Modern Physics 79, 1-52 (2007).

17. Garrabos, Y., Wunenburger, R., Hegseth, J., Lecoutre-Chabot, C. \& Beysens, D. Critical boiling phenomena observed in microgravity. in AIP Conference Proceedings vol. 504 737-743 (American Institute of Physics, 2000).

18. Garrabos, Y. et al. Thermoconvectional phenomena induced by vibrations in supercritical S F 6 under weightlessness. Physical Review E 75, 056317 (2007).

19. Zappoli, B., Beysens, D. \& Garrabos, Y. Heat Transfers and Related Effects in Supercritical Fluids. vol. 108 (Springer Netherlands, 2015).

20. J. G. Collier and J. R. Thome, Convective Boiling and 673 Condensation (Clarendon Press, 1994)

21. Johnson, S. G. REFPROP. NIST https://www.nist.gov/srd/refprop (2013).

22. Parahovnik, A., Asadzadeh, M., Vasu, S. S. \& Peles, Y. Subcooled Flow Boiling of Carbon Dioxide Near the Critical Point Inside a Microchannel. Phys. Rev. Applied 14, 054050 (2020).

23. Cheng, L., Ribatski, G., Moreno Quibén, J. \& Thome, J. R. New prediction methods for CO2 evaporation inside tubes: Part I - A two-phase flow pattern map and a flow pattern based phenomenological model for two-phase flow frictional pressure drops. International Journal of Heat and Mass Transfer 51, 111-124 (2008). 
24. Bolmatov, D. et al. The Frenkel Line: a direct experimental evidence for the new thermodynamic boundary. Scientific reports 5, 15850 (2015).

25. Trasatti, S. Atkins' Physical Chemistry, P. Atkins, J. De Paula, Oxford University Press, Oxford, UK (2006), ISBN: 0198700725. (Pergamon, 2007).

26. Mareev, E. et al. Anomalous behavior of nonlinear refractive indexes of CO 2 and Xe in supercritical states. Optics express 26, 13229-13238 (2018).

27. Gopal, E. R. Critical opalescence. Resonance 5, 37-45 (2000).

28. White, J. A. \& Maccabee, B. S. Temperature dependence of critical opalescence in carbon dioxide. Physical Review Letters 26, 1468 (1971).

29. Abdel-Azim, A. A. A. \& Munk, P. Light scattering of liquids and liquid mixtures. 1. Compressibility of pure liquids. Journal of Physical Chemistry 91, 3910-3914 (1987).

30. Onuki, A., Hao, H. \& Ferrell, R. A. Fast adiabatic equilibration in a single-component fluid near the liquid-vapor critical point. Physical Review A 41, 2256 (1990).

31. Einstein, A. Ann. Phys. (Leipzig) 1910, 33, 1275.

32. Chaikina, Yu. A. Molecular Model for Critical Opalescence of Carbon Dioxide. Russ. J. Phys. Chem. B 12, 1182-1192 (2018).

33. Span, R. \& Wagner, W. A New Equation of State for Carbon Dioxide Covering the Fluid Region from the Triple-Point Temperature to $1100 \mathrm{~K}$ at Pressures up to $800 \mathrm{MPa}$. Journal of Physical and Chemical Reference Data 25, 1509-1596 (1996).

34. Aminabhavi, T. M., Phayde, H. T. S. \& Khinnavar, R. S. Densities, Refractive Indices, Speeds of Sound and Shear Viscosities of Diethylene Glycol Dimethyl Ether Methyl Salicylate at Temperatures from 298.15 to 318.15 K. Collect. Czech. Chem. Commun. 59, 1511-1524 (1994).

35. Moriyoshi, T., Kita, T. \& Uosaki, Y. Static relative permittivity of carbon dioxide and nitrous oxide up to 30 MPa. Berichte der Bunsengesellschaft für physikalische Chemie 97, 589-596 (1993).

36. Bejan, A. Convection heat transfer. (John wiley \& sons, 2013). 
37. Hall, W. B., Jackson, J. D. \& Watson, A. Paper 3: A Review of Forced Convection Heat Transfer to Fluids at Supercritical Pressures. Proceedings of the Institution of Mechanical Engineers, Conference Proceedings 182, 10-22 (1967).

38. Moffat, R. J. Describing the uncertainties in experimental results. Experimental thermal and fluid science 1, 3-17 (1988).

39. Onuki, A., Hao, H. \& Ferrell, R. A. Fast adiabatic equilibration in a single-component fluid near the liquid-vapor critical point. Phys. Rev. A 41, 2256-2259 (1990).

Table

Table 1-List of experiments and their conditions

\begin{tabular}{|c|c|c|c|c|c|c|c|}
\hline No. & $\mathrm{P}_{\mathrm{r}}$ & $\mathrm{T}_{\mathrm{r}}$ & $\mathrm{T}_{0}[\mathrm{~K}]$ & $\mathrm{T}_{\mathrm{sat}}[\mathrm{K}]$ & $\mathrm{G}\left[\mathrm{kg} \cdot \mathrm{m}^{-2} \mathrm{~s}^{-1}\right]$ & $\mathrm{q}^{\prime \prime}\left[\mathrm{W} \cdot \mathrm{cm}^{-2}\right]$ & $I_{T_{0}} / I_{T}$ \\
\hline 1 & 0.86 & 0.978 & 296.2 & 297.42 & 523.00 & 7.14 & 1.32 \\
\hline 2 & 0.88 & 0.982 & 296.24 & 298.69 & 280.00 & 4.20 & 1.33 \\
\hline 3 & 0.90 & 0.984 & 295.67 & 299.28 & 484.30 & 6.88 & 1.26 \\
\hline 4 & 0.91 & 0.986 & 295.73 & 300.01 & 547.51 & 6.66 & 1.62 \\
\hline 5 & 0.91 & 0.986 & 296.0 & 299.90 & 413.00 & 5.13 & 1.51 \\
\hline 6 & 0.95 & 0.993 & 296.6 & 301.9 & 712.00 & 12.50 & 1.62 \\
\hline 7 & 0.98 & 0.997 & 296.36 & 303.1 & 474.00 & 9.20 & 1.64 \\
\hline 8 & 0.99 & 0.998 & 296.46 & 303.57 & 464.88 & 6.75 & 1.5 \\
\hline
\end{tabular}




\section{Figures}

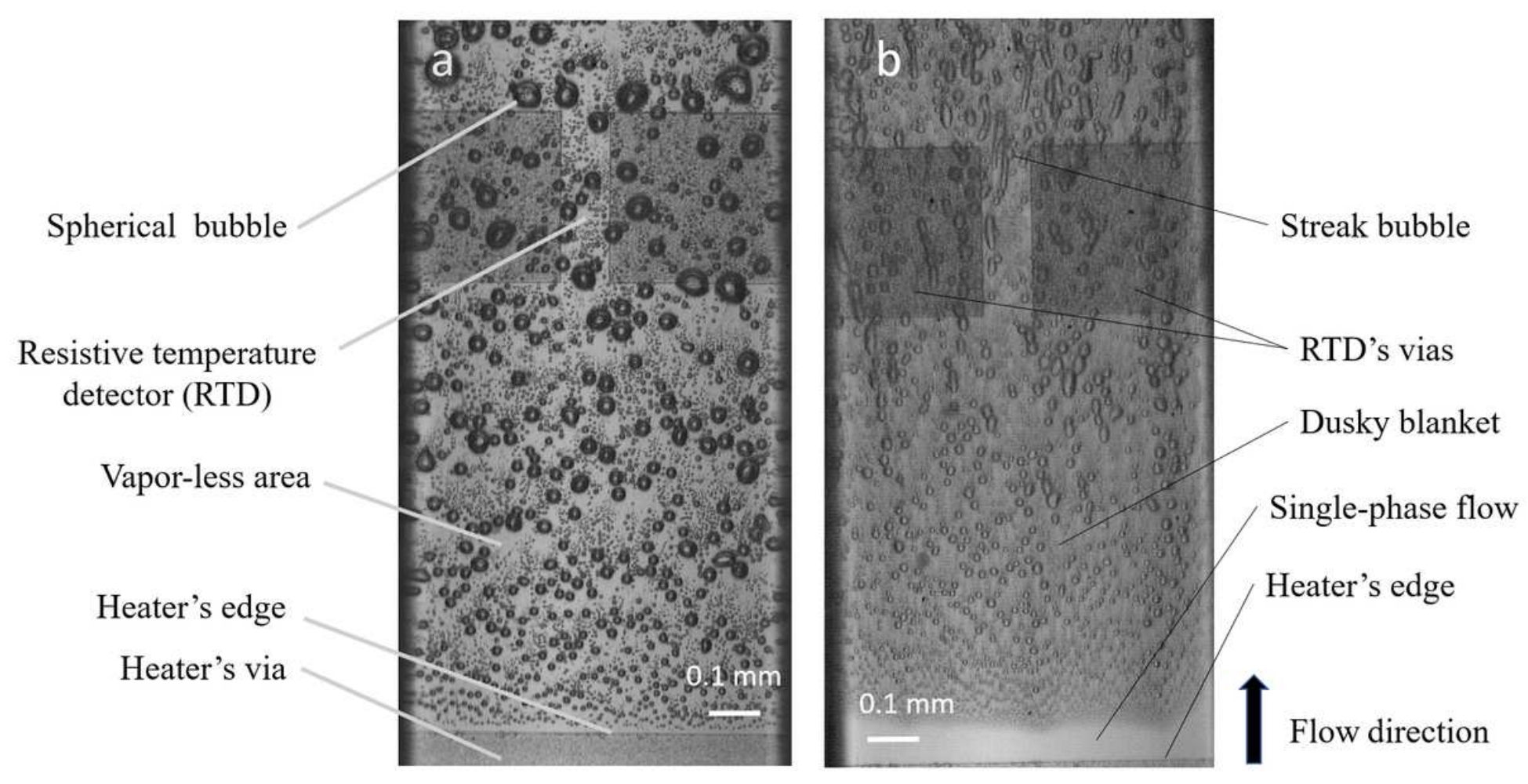

\section{Figure 1}

Shift in flow pattern as the reduced pressure approaches unity: a) At reduced pressures below 0.95 , nuclei bubbles with an initial diameter of $2 \mu \mathrm{m}$ to $5 \mu \mathrm{m}$ formed and gradually grew to diameter of $\sim 50 \mu \mathrm{m}$ (shown: $\operatorname{Pr}=0.86, \mathrm{G}=523 \mathrm{~kg} / \mathrm{m} 2 \mathrm{~s}$, and q" $=7.14 \mathrm{~W} / \mathrm{cm} 2$ ) as they propagated downstream. As the bubble grew, they formed vapor-less regions in their wake. b) At reduced pressures above 0.95, a bi-pattern composed of vapor streaks above the heater and small $2 \mu \mathrm{m}$ nuclei bubbles, which formed inside a distinct dusky layer below the heater was observed (shown: $\operatorname{Pr}=0.98, \mathrm{G}=474 \mathrm{~kg} / \mathrm{m} 2 \mathrm{~s}$, and q" $=9.2 \mathrm{~W} / \mathrm{cm} 2$ ). Vapor downstream propagation was considerably slower compared to lower pressures. The change in bubble shape and pattern was consistent with experimental studies performed in a microgravity environment17. 

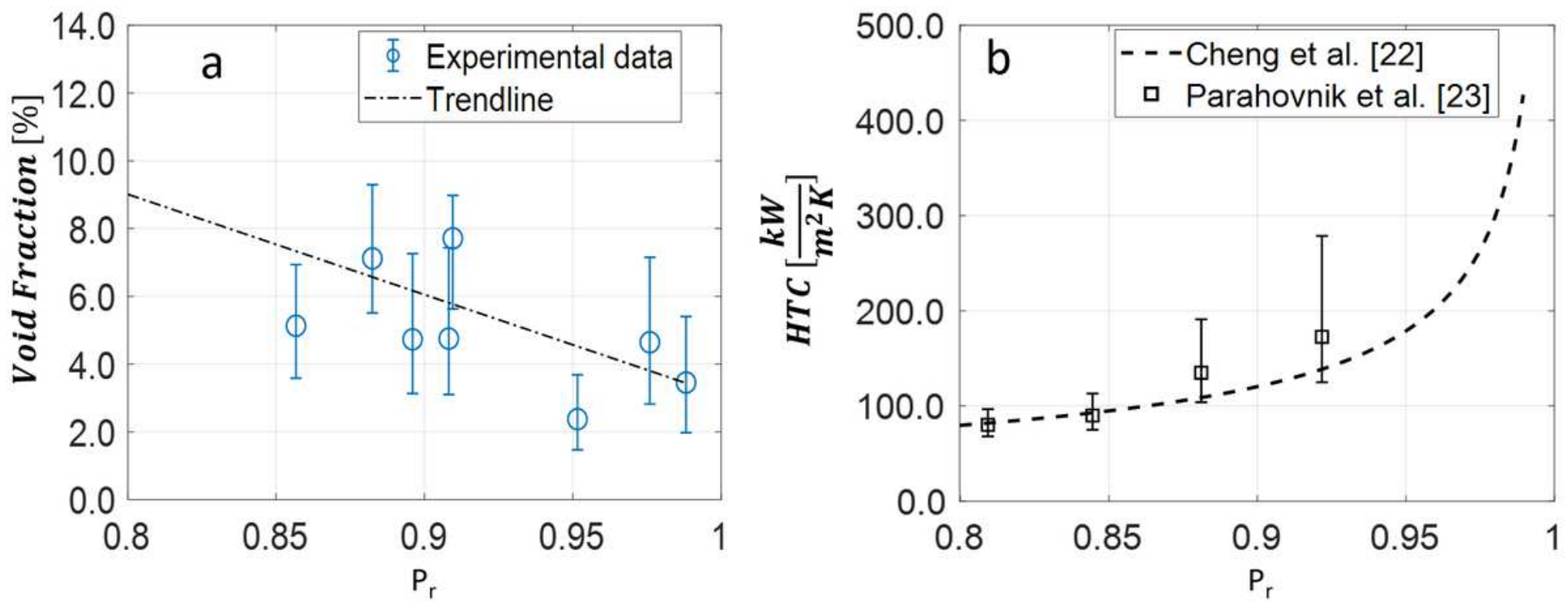

Figure 2

Vapor fraction and heat transfer coefficient trends as the reduced pressure approached unity. a) The void fraction decreased with reduced pressure, while b) the heat transfer coefficient increased.
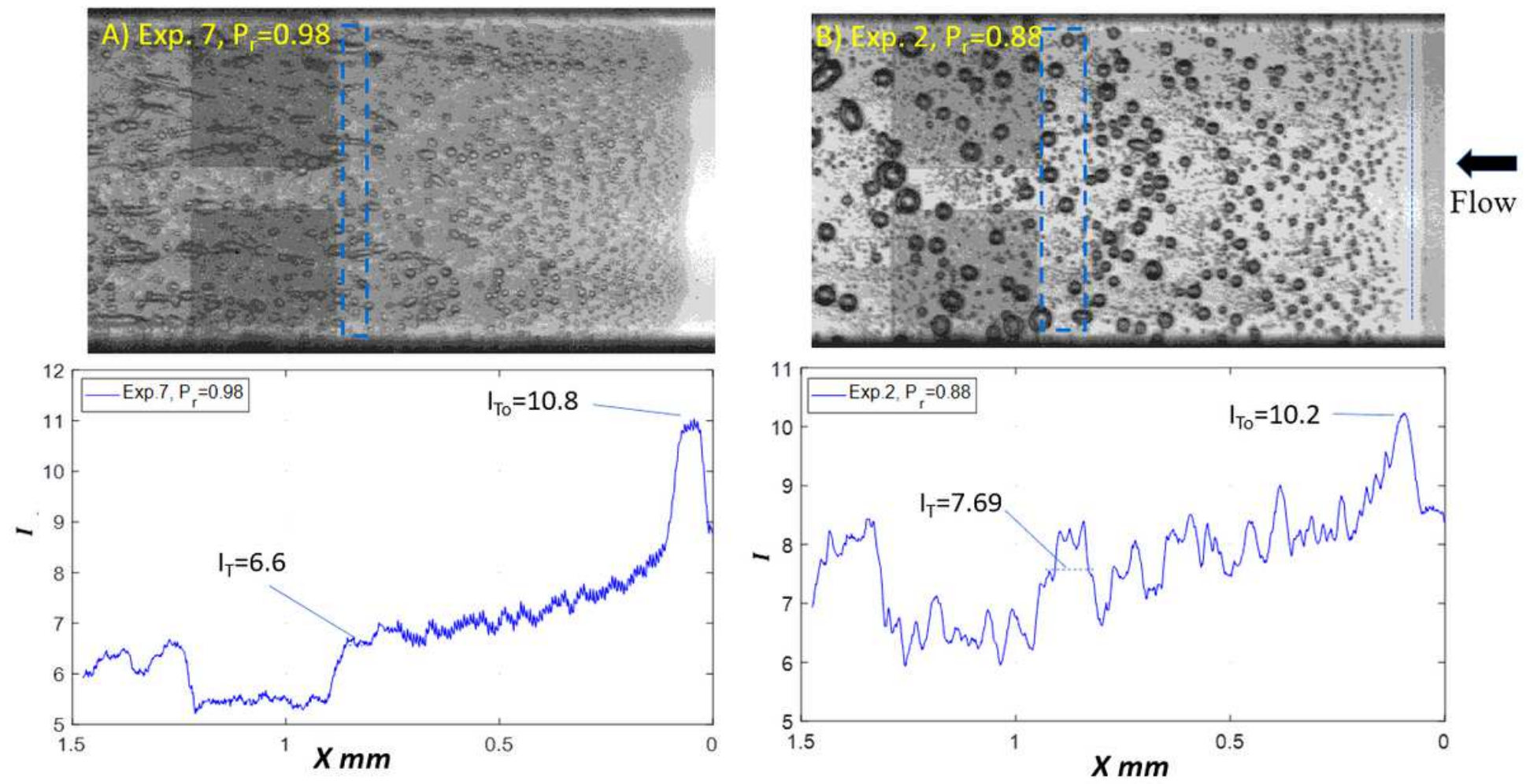

Figure 3

Returned light intensity along the flow direction. The intensity of the returned light (I) was calculated as an average of the local intensities of the cross-section. The returned light intensity at the inlet temperature (ITo) was sampled as close as possible to the heaters via. The returned light intensity at the downstream temperature was sampled before the RTD's vias to maintain similar background. The mean returned light 
intensity of the cross-section dropped as the flow was heated. The bubbles were expressed as variations from the mean returned light intensity value. As the reduced pressure approached unity, these variations were reduced to moderate signal noise.

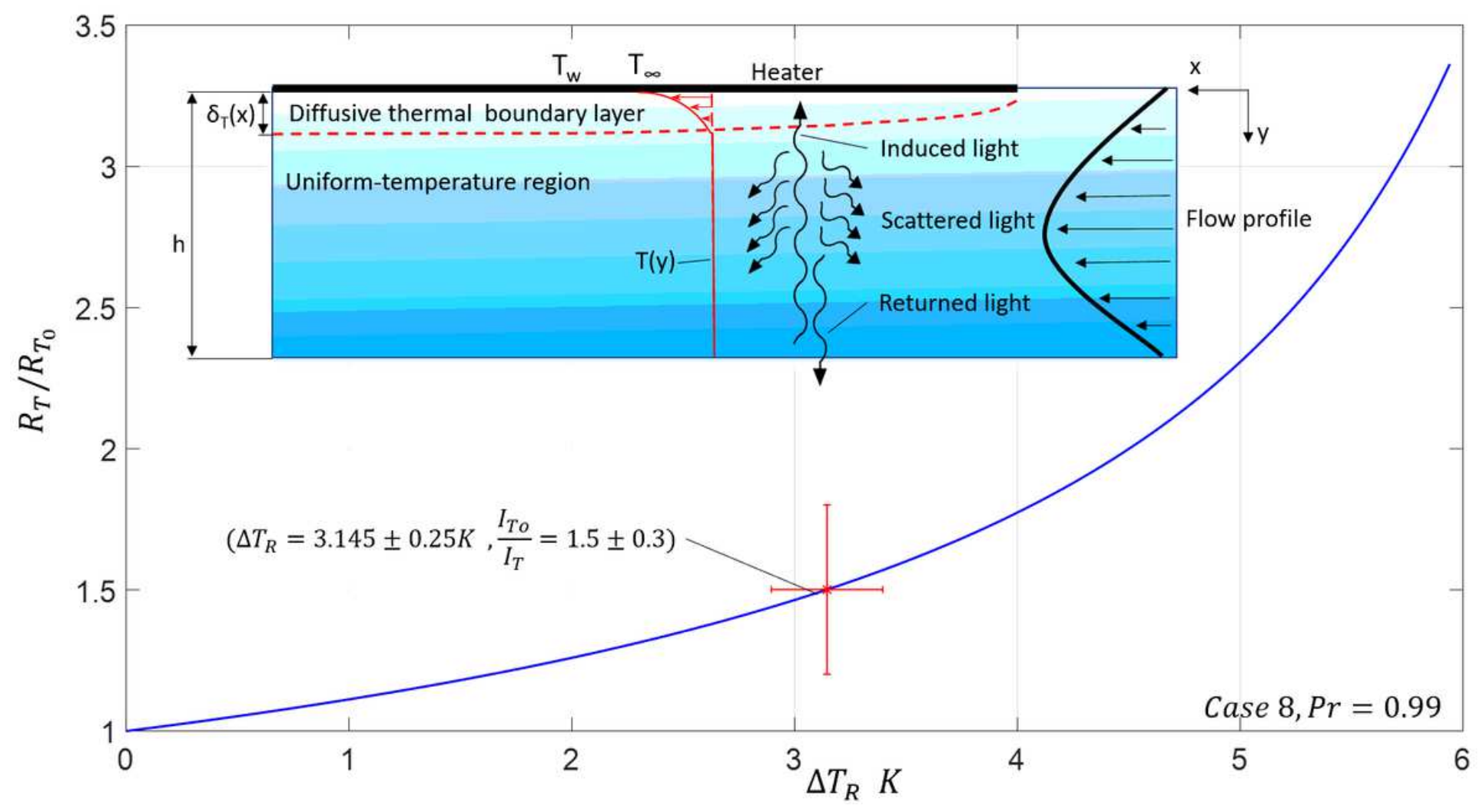

\section{Figure 4}

Calculation of the increase in temperature according to returned light density measurements. The scattering ratio (R/RTo) as a function of the bulk temperature increase $(\triangle T R)$ at a reduced pressure of 0.99 . The theoretical curve obtained from Eq. 2 corresponds to a measured value of 1.5 at a temperature rise of $3.145 \mathrm{~K}$. 


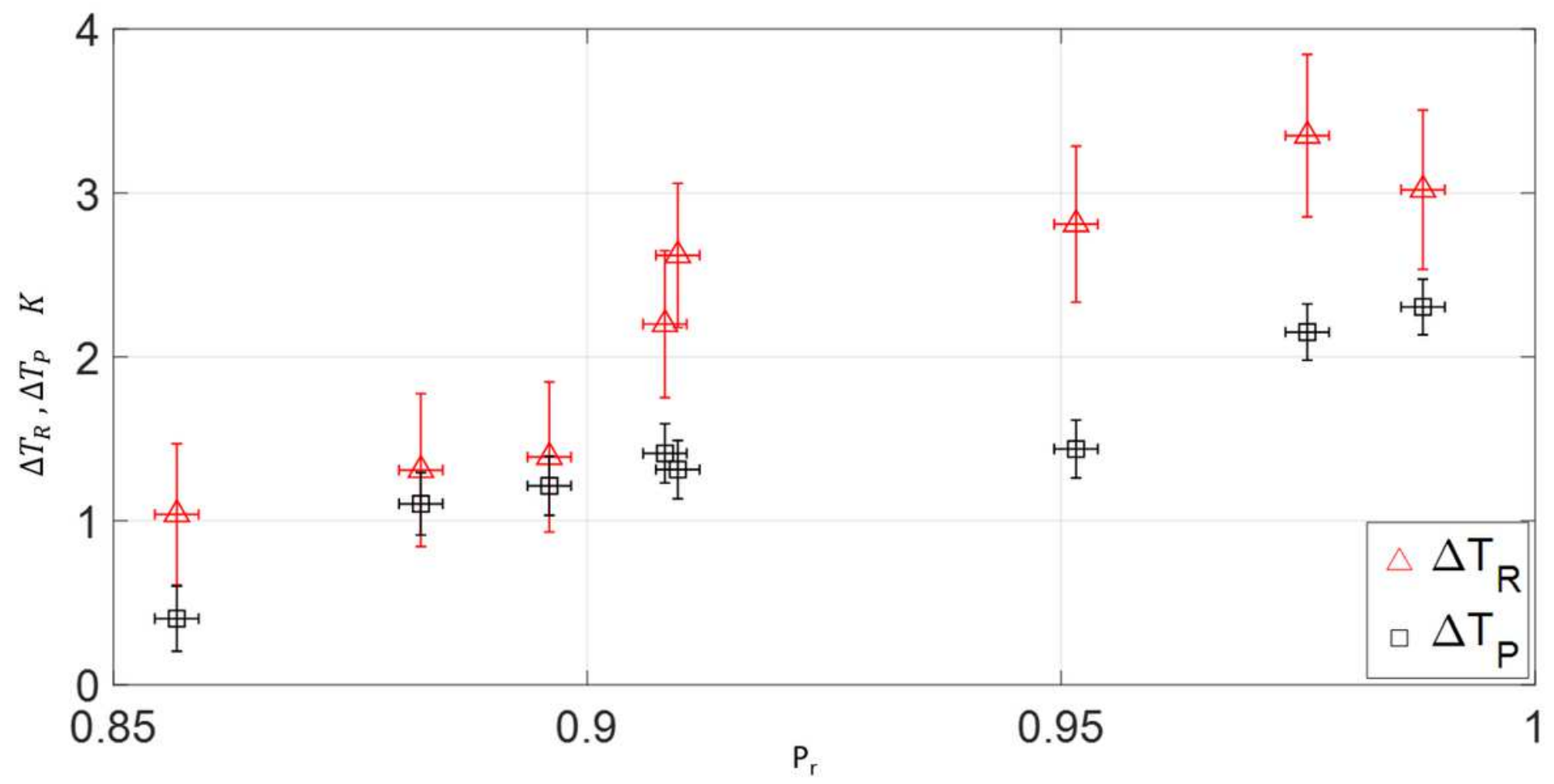

Figure 5

Increase in bulk's fluid temperature through the piston effect analysis ( $\triangle T P) 39$ and through critical opalescence measurements ( $\Delta \mathrm{TR})$. The mean average error between $\Delta T R$ and $\Delta T P$ was $35 \%$ provided sufficient confidence that the fluid's bulk temperature outside the boundary layer increased mainly due to the piston effect.

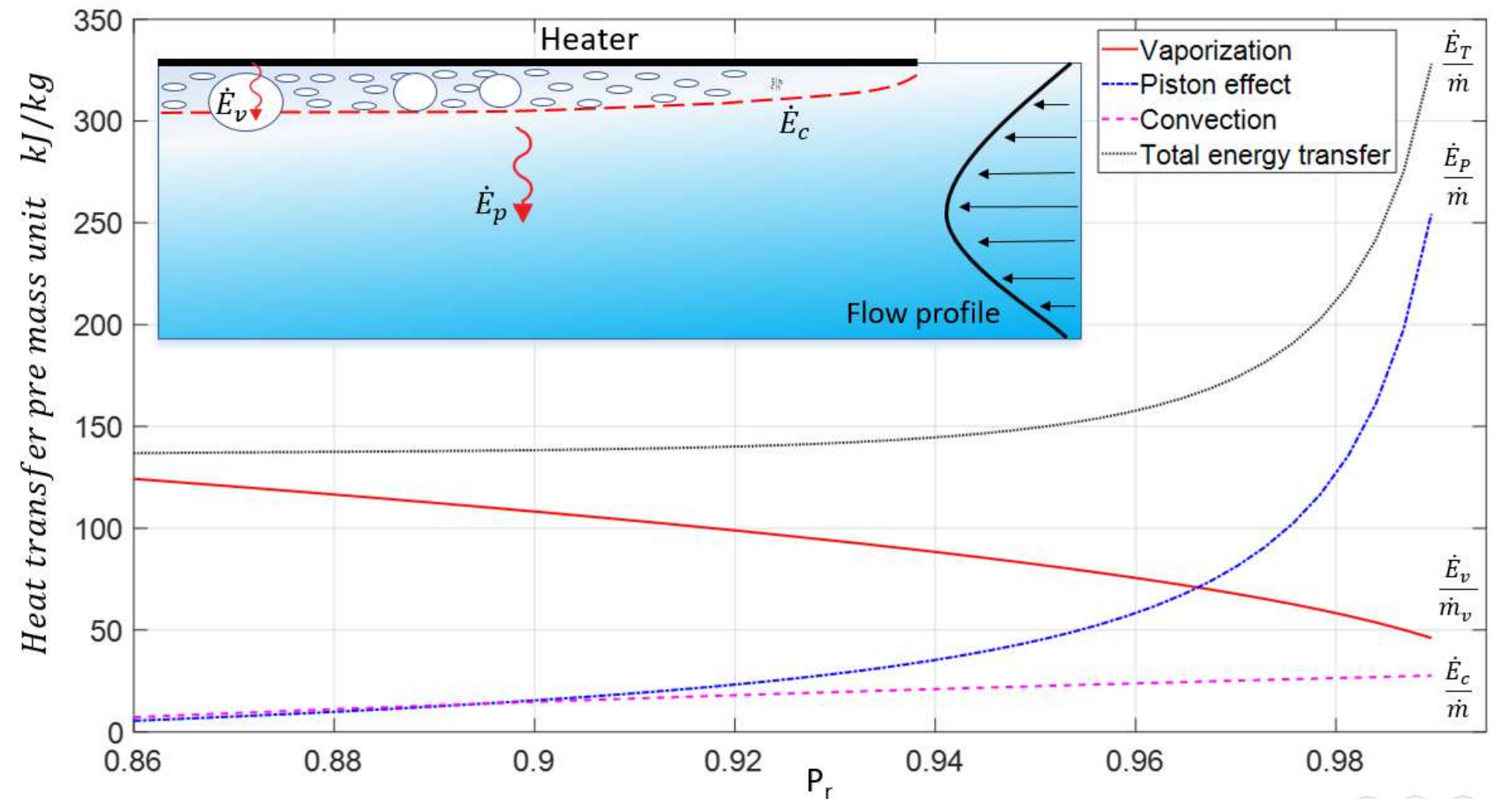


Figure 6

Transition of heat transfer modes towards adiabatic thermalization (i.e., piston effect).

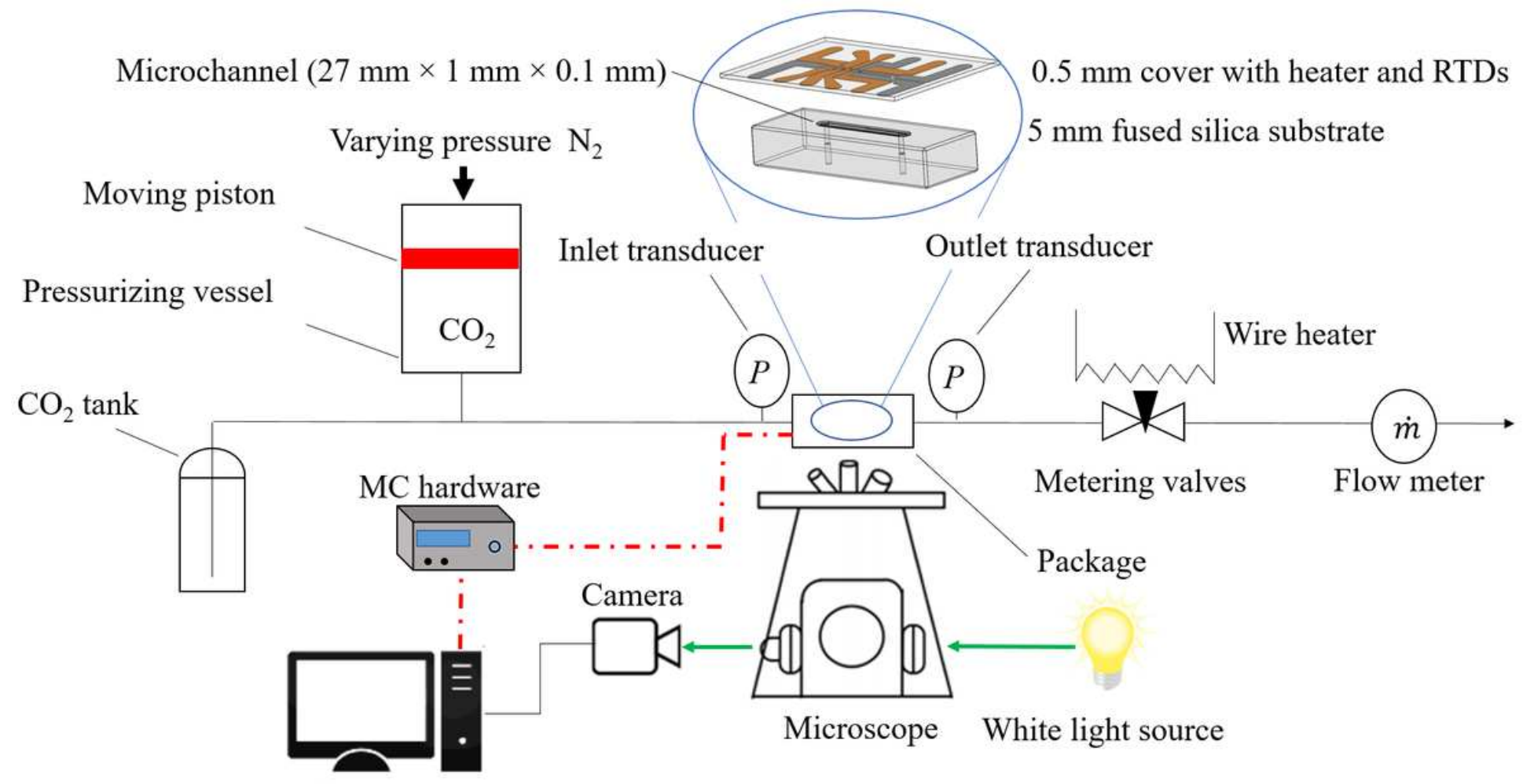

Computer

Figure 7

Experimental setup and microfluidic device.

\section{Supplementary Files}

This is a list of supplementary files associated with this preprint. Click to download.

- A.ParahovnikandY.Pelessupplementarymaterials.docx 